\title{
Ekstraksi Pigmen Klorofil Total Pada Mikroalga Dunaliella sp. Yang Telah diberi Perlakuan Timbal Asetat
}

\author{
(Total Chlorophyll Pigment Extraction in Microalgae Dunaliella sp. Who has been \\ treated with lead acetate) \\ Oscar M. Lamohamad ${ }^{1 *}$, Kurniati Kemer ${ }^{1^{*}}$, Desy M.H. Mantiri ${ }^{1^{*}}$, James Paulus ${ }^{1^{*}}$, Ester \\ Angkow $^{1^{*}}$, Adnan S. Wantasen ${ }^{2^{*}}$, \\ 1Program Studi IImu Kelautan, Fakultas Perikanan dan Ilmu Kelautan Universitas Sam Ratulangi \\ Manado - Sulawesi Utara, Indonesia. \\ 2Fakultas Perikanan dan IImu Kelautan Universitas Sam Ratulangi Manado - \\ Sulawesi Utara, Indonesia. \\ *Corresponding Author: oscarlamohamad03@gmail.com
}

\begin{abstract}
Heavy metals such as lead are compounds that can cause toxic effects if they enter the body of living things. Dunaliella sp. is one of the marine organisms that is susceptible to changes or ecological pressure so that it is the main target of being exposed to pollutants such as heavy metals and so on, so it is necessary to conduct research to determine how the effect of lead acetate compounds on the growth and total chlorophyll content of Dunaliella micro algae. sp. The results of this study indicate that the growth of Dunaliella sp microalgae on the control culture media and the lead treatment media has a very different growth, the control media has normal growth, while the total chlorophyll content of the 14th day in the control media is $80.49 \mu \mathrm{g} / \mathrm{ml} .30 \mathrm{ppm} 54.79 \mu \mathrm{g} / \mathrm{ml}, 50 \mathrm{ppm} 50.02 \mu \mathrm{g} / \mathrm{ml}$ and $100 \mathrm{ppm} 9.13 \mu \mathrm{g} / \mathrm{ml}$. While the total chlorophyll content of the 30th day in the control media was $34.99 \mu \mathrm{g} / \mathrm{ml}, 30 \mathrm{ppm} 44.657 \mu \mathrm{g} / \mathrm{ml}, 50 \mathrm{ppm} 26.136 \mu \mathrm{g} / \mathrm{ml}$ and $100 \mathrm{ppm} 5.58 \mu \mathrm{g} / \mathrm{ml}$.
\end{abstract}

Keywords: microalgae, Dunaliella sp, chlorophyll, lead acetate

Logam berat seperti timbal merupakan senyawa yang dapat menimbulkan efek toksik jika masuk dalam tubuh makhluk hidup. Dunaliella merupakan salah satu organisme laut yang rentan terhadap perubahan atau tekanan ekologis sehingga menjadi sasaran utama terkena bahan-bahan pencemar seperti logam berat dan lain sebagainya, sehingga perlu diadakan penelitian untuk mengetahui bagaimana pengaruh senyawa timbal asetat terhadap pertumbuhan dan kandungan klorofil total dari mikro alga Dunaliella sp.

Hasil penelitian ini menunjukan bahwa pertumbuhan mikroalga Dunaliella sp pada media kultur kontrol dan media perlakuan timbal memiliki pertumbuhan yang sangat berbeda nyata, pada media kontrol memiliki pertumbuhan yang normal sedang Kandungan klorofil total hari ke-14 pada media

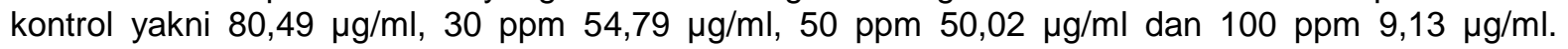
Sedangkan kandungan klorofil total hari ke-30 pada media kontrol yaitu 34,99 $\mu \mathrm{g} / \mathrm{ml}, 30 \mathrm{ppm} \mathrm{44,657}$ $\mu \mathrm{g} / \mathrm{ml}, 50 \mathrm{ppm} 26,136 \mu \mathrm{g} / \mathrm{ml}$ dan $100 \mathrm{ppm} 5,58 \mu \mathrm{g} / \mathrm{ml}$.

Kata Kunci: Mikroalga, Dunaliella sp, Klorofil, Timbal asetat 


\section{PENDAHULUAN}

Alga merupakan organisme autotrof yang tidak memiliki akar, batang dan daun sejati. Tumbuhan alga hidup-nya di dalam air laut dan memiliki plastisida yaitu organel sel (pigmen) yang berfungsi untuk melakukan proses fotosintesis. Alga memiliki sifat uniseluler dan multiseluler yang terdiri dalam dua kelompok, yaitu makroalga dan mikroalga. Makroalga yang berukuran besar dan dapat dilihat secara langsung dengan mata sedangkan mikroalga yang berukuran kecil harus dilihat dengan menggunakan mikroskop (Romihartono dan Juwana 2005). Mikroalga dapat memberikan informasi mengenai kondisi perairan atau disebut juga sebagai bio-indikator yaitu untuk mengevaluasi kualitas dan tingkat kesuburan suatu perairan, (Simanjuntak $d k k_{s}$ 2016).

Salah satu yang dapat
mempengaruhi kualitas dan tingkat kesuburan perairan adalah pencemaran logam berat antara lain logam timbal $(\mathrm{Pb})$. Menurut Purnomo dan Muchyiddin (2007), $\mathrm{Pb}$ merupakan salah satu pencemar yang dipermasalahkan karena bersifat sangat toksik dan tergolong sebagai bahan buangan beracun dan berbahaya. Bila konsentrasi logam berat melebihi ambang batas dapat menimbulkan bahaya karena tingkat toksisitasnya akan mengganggu organisme yang ada di perairan baik langsung maupun tidak langsung (Widowati et al., 2008). Dunaliella sp merupakan salah satu organisme yang sangat rentan terhadap adanya logam timbal. sehingga perlu diadakan penelitian untuk mengetahui bagaimana pengaruh senyawa timbal asetat terhadap pertumbuhan dan kandungan klorofil total dari mikro alga Dunaliella sp

\section{METODOLOGI PENELITIAN}

\section{Pembuatan Kultur Mikroalga Dunaliella} sp.

Alga mikro yang digunakan adalah jenis Dunaliella sp, dalam penelitian ini di ambil dari stok yang ada di laboratorium Teknologi Akuakultur FPIK-UNSRAT. Air laut yang digunakan sebagai medium alga disaring dengan menggunakan alat penyaring air aspirator yang dilengkapi dengan kertas saring (whatman) berukuran pori-pori 0,45 $\mu \mathrm{m}$ dan di sterilisasi dengan autoclave. Kemudian air laut yang sudah disterilkan ditambahkan nutrien media walne sebanyak $1000 \mu \mathrm{l}$ yang belum berisikan mikro alga dan diaduk hingga merata. Kemudian air laut yang sudah tercampur nutrien media walne dibagikan kedalam 5 labu erlemeyer dan ditambahkan mikro alga Dunaliella sp yang selanjutnya disimpan kedalam lemari kultur. Untuk mengetahui kepadatan mikroalga dapat dihitung dengan alat haemocytometer dan mikroskop 40x, pengamatan setiap hari dilakukan dengan lima kali ulangan $(5 \times)$.

\section{Pemberian Timbal Asetat}

Mikroalga Dunaliella sp pada pertumbuhan hari ke-13 diberikan perlakuan dengan senyawa timbal asetat. Dalam 5 erlemeyer yang terisi kultur mikroalga digabungkan dalam satu wadah dan dipisahkan kembali dalam 4 erlemeyer untuk diberikan perlakuan dengan konsentrasi 30 ppm, 50 ppm, 100 ppm dan kontrol. Selanjutnya disimpan ke dalam lemari kultur untuk dilakukan pengamatan setiap hari pada jam yang sama dengan lima kali ulangan dalam setiap sampel.

\section{Ekstraksi Pigmen Klorofil Total}

Ekstraksi pigmen menggunakan metode Harbone (1987), sampel mikroalga yang 
pertumbuhan hari ke-14 dan hari ke 30 disentrifus dengan kecepatan 3000 rpm selama 15 menit untuk diekstraksi di dalam ruangan gelap. Mikroalga Dunaliella sp. diaduk dalam larutan aseton. Sampel yang berwarna hijau dimasukan dalam labu pemisah dan dipisahkan dengan pelarut organik melalui metode Pratt (1994). Larutan organik petroleum eter proanalisis dimasukan dan didiamkan sampai terlihat dua lapisan.

Lapisan atas : Hijau daun dalam petroleum eter.

Lapisan bawah : Hydro aseton, Putih keruh.

Lapisan yang berwarna putih keruh dalam hydro aseton dibuang dan lapisan atas diambil. Tahap ini didapat pigmen yang bersih dari aseton dan tahap selanjutnya akan dilakukan penyerapan gelombang maksimum menggunakan spektrofotometer. Hasil dari spektrofotometer digunakan untuk mengetahui nilai kandungan oigmen total pada ekstraksi mikroalga Dunaliella sp. Menentukan kandungan klorofil total memakai panduan rumus Harborne, J.B. (1987) dihitung dengan rumus berikut:

- Pigmen Klorofil total = $17,3 \mathrm{~A}_{646}+7,18 \mathrm{~A}_{633} \mathrm{mg} / \mathrm{l}$

\section{HASIL DAN PEMBAHASAN}

\section{Pertumbuhan Dunaliella sp. Sebelum Perlakuan}

Pertumbuhan Dunaliella sp. Sebelum Perlakuan. Hasil penelitian pengamatan pertumbuhan mikroalga Dunaliella sp. dilakukan dengan menghitung kepadatan mikroalga Dunaliella sp. tanpa pemberian senyawa timbal asetat dan dengan pemberian senyawa timbal asetat. Pada pengamatan hari ke 1 sampai ke 13 belum dilakukan pemberian senyawa timbal asetat, pertumbuhan mikroalga Dunaliella sp. terjadi proses penambahan jumlah sel yang di amati setiap hari dengan menghitung kepadataan populasi sel.

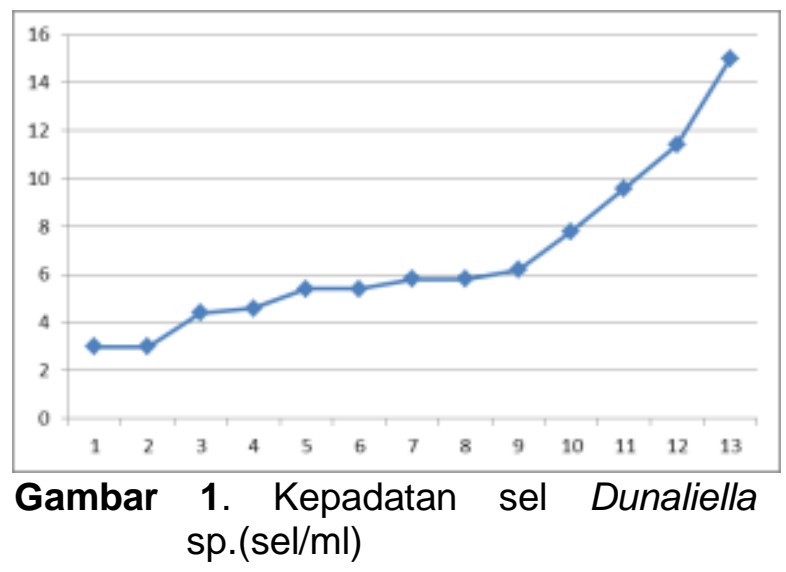

pada penelitian pada hari ke 1 sampai hari ke 13 mengalami penambahan jumlah sel yang normal pada mikroalga umumnya. Kepadatan sel mikroalga Dunaliella sp. hari ke 1 sampai hari ke 2 memiliki jumlah kepadatan sel yang sama yaitu $3 \mathrm{sel} / \mathrm{ml}$. pada hari ke 1 sampai hari ke 2 sel mikroalga sedang beradaptasi terhadap media tumbuhnya. Pada hari ke 3 perubahan penambahan sel terjadi disebabkan mikroalga mulai mengambil nutrient yang diberikan dalam kultur sebagai makanan untuk memulai pertumbuhan atau pembelahan sel. Pada hari ke-9 sampai ke-11 mengalami penambahan sel yang sangat pesat, dimana pertumbuhan mikroalga memasuki fase eksponensial. Pada hari ke-11 jumlah sel mikroalga yaitu $11,4 \mathrm{sel} / \mathrm{ml}$. Pada hari ke-13 terjadi penambahan jumlah sel yang sangat signifikan yaitu dari $11,4 \mathrm{sel} / \mathrm{ml}$ menjadi 15 sel ml. Pada penelitian Balaria dkk (2017), fase eksponensial pada pertumbuhan mikroalga Dunaliella sp yang dikultur terjadi pada hari ke 9 dan pada penelitian Pranajaya $d k k$ (2014) fase eksponensial pada pertumbuhan mikroalga P. cruentum terjadi pada hari ke2 sampai hari ke-4. Perbedaan masa eksponensial yang terjadi disebabkan karena mikroalga mengalami masa adaptasi yang berbeda-beda terhadap media kulturnya. 


\section{Pertumbuhan Dunaliella sp. Setelah Perlakuan}

Pemberian senyawa timbal asetat diberikan pada mikroalga Dunaliella $\mathrm{sp}$. saat di hari ke-13 yakni pada fase eksponensial. Hari ke-14 pada media kontrol mengalami penurunan jumlah sel, yaitu dimana jumlah sel pada hari sebelumnya $15 \mathrm{sel} / \mathrm{ml}$ dan pada hari ke 14 menjadi $13 \mathrm{sel} / \mathrm{ml}$. penurunan julah sel diduga karena adanya kompetisi disaat fase optimum. Kompetisi antara sel Dunaliella sp. juga berpengaruh terhadap kemampuan pembelahan sel sehingga mengakibatkan produksi sel semakin berkurang (Abidin \& Trihandaru, 2009). Namun jumlah sel pada media kontrol mengalami penurunan yang sangat kecil dibandingkan dengan dengan 3 media kultur lainnya. Pada 3 media kultur lainnya yaitu media kultur yang telah diberi perlakuan timbal asetat dengan konsentrasi 30 ppm, 50 ppm dan 100 ppm mengalami penurunan jumlah sel atau kematian sel yang sangat nyata.



Gambar 2. Kepadatan sel Dunaliella sp. (sel/ml).

Berdasarkan gambar di atas media kultur yang diberi perlakuan senyawa timbal asetat mengalami penurunan jumlah sel yang sangat drastis hal ini berbeda dengan perkembangan jumlah sel pada media kontrol. Jumlah sel pada hari ke-13 sebelum diberi perlakuan timbal aset yaitu $15 \mathrm{sel} / \mathrm{ml}$ dan hari ke-14 pada ketiga media yang sudah diberi timbal asetat ini mengalami kematian terlihat dari penurunan jumlah sel. Jumlah sel hari ke14 pada $30 \mathrm{ppm}$ yaitu $5.6 \mathrm{sel} / \mathrm{ml}$, pada 50 ppm yaitu $4.6 \mathrm{sel} / \mathrm{ml}$ dan $100 \mathrm{ppm}$ jumlah sel yakni $3.4 \mathrm{se} / \mathrm{ml}$. Pertumbuhan sel mikroalga Dunaliella sp. dengan pemberian senyawa timbal asetat mengalami kematian yang cukup drastis isebabkan karena nutrien media kultur yg berkurang dan konsentrasi logam berat timbal asetat yang semakin toksik. Menurut Wong dkk (1995), Penurunan jumlah sel disebabkan karena logam berat sangat beracun bagi mikroalga dan dapat menghambat pertumbuhan sel apabila diberikan dalam jumlah yang berlebihan (Kemer, dkk, 2020).

Analisis Ekstrak klorofil Total dari Dunaliella sp. pada Fase Eksponensial dan Fase Kematian 
1. Serapan spektrofotometer Ekstrak klorofil total Dunaliella sp hari ke-14

Serapan spektrofotometer pada ekstrak total Dunaliella sp. kontrol, perlakuan $100 \mathrm{ppm}, 50 \mathrm{ppm}$ dan $30 \mathrm{ppm}$ disaat fase eksponensial menghasilkan panjang gelombang yang berbeda, pada ekstrak kontrol memiliki panjang gelombang 412, $662 \mathrm{~nm}$ (gambar A); pada



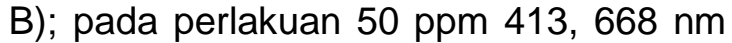
(gambar C) dan pada perlakuan 100 ppm 412, $662 \mathrm{Nm}$ (gambar D).
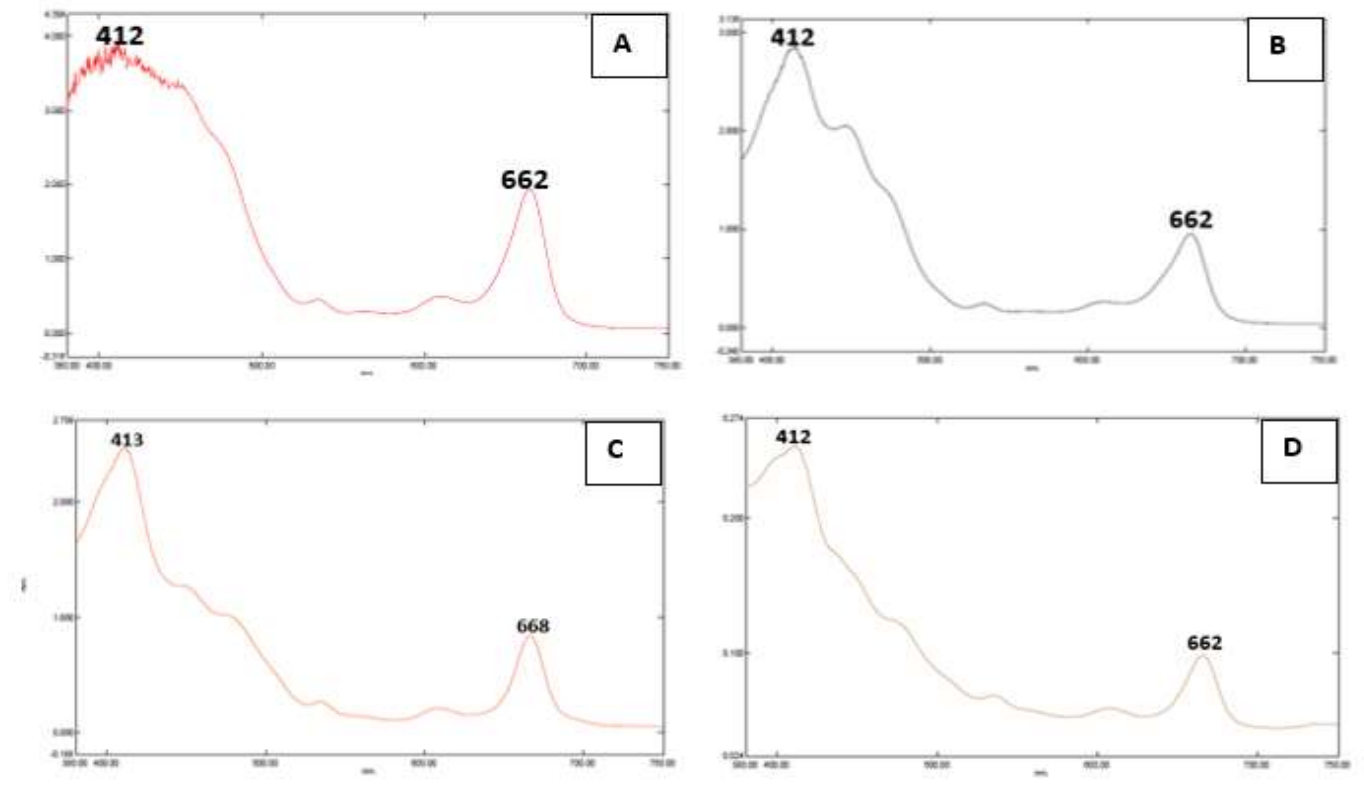

Gambar 3. Puncak gelombang spektrofotmeter ekstraksi mikroalga Dunaliella sp. pada hari ke-14

2 Serapan Spektrofotometer Ekstrak klorofil total Dunaliella sp hari ke-30.

Serapan spektrofotometer pada ekstrak total Dunaliella sp. perlakuan 30 ppm, 50 ppm dan 100 ppm disaat fase kematian menghasilkan panjang gelombang yang berbeda, pada ekstrak kontrol memiliki dua puncak gelombang dengan panjang gelombang yaitu 414,663 $\mathrm{nm}$ ( gambar A); perlakuan 30 ppm 412, $662 \mathrm{~nm}$ (gambar B); pada perlakuan 50 ppm 413, 662 nm (gambar C); dan pada perlakuan 100 ppm 413, 662 nm (gambar D).Hasil spektogram dari masing-masing ekstraksi dapat dilihat pada Gambar 4. 



Gambar 4. Puncak gelombang spektrofotmeter ekstraksi mikroalga Dunaliella sp. pada hari ke-30.

Spektogram dari masing-masing ekstrak tersebut dapat menentukan menentukan kandungan klorofil total yang terdapat pada masing-masing ekstrak. Menentukan kandungan klorofil total memakai panduan rumus Harborne, J.B. (1987) dihitung dengan rumus berikut:

klorofil total $=17,3 \mathrm{~A}_{646}+7,18 \mathrm{~A}_{633} \mathrm{mg} / \mathrm{l}$ 
Tabel 1. Nilai kandungan klorofil total mikroalga Dunaliella sp

\begin{tabular}{|c|c|c|c|c|}
\hline \multirow{2}{*}{$\begin{array}{c}\text { Hari } \\
\text { Ke-14 }\end{array}$} & \multicolumn{4}{|c|}{$\begin{array}{c}\text { Kandungan klorofil Total } \\
(\mu \mathrm{g} / \mathrm{ml})\end{array}$} \\
\cline { 2 - 5 } & Kontrol & $30 \mathrm{ppm}$ & $50 \mathrm{ppm}$ & $100 \mathrm{ppm}$ \\
\cline { 2 - 5 } & 80,49 & 54,79 & 50,02 & 9,13 \\
\hline \multirow{4}{*}{$\begin{array}{c}\text { Kandungan klorofil Total } \\
\text { Hag/ml })\end{array}$} \\
\cline { 2 - 5 } Ke-30 & Kontrol & $30 \mathrm{ppm}$ & $50 \mathrm{ppm}$ & $100 \mathrm{ppm}$ \\
\cline { 2 - 5 } & 34,99 & 44,657 & 26,136 & 5,58 \\
\hline
\end{tabular}

Berdasarkan Tabel 1 hari ke-14 dapat dilihat perbedaan kandungan klorofil total Dunaliella sp pada 4 media kultur berbeda yang diekstrak pada hari ke 14, dimana mikroalga berada diantara fase eksponensial dan fase stasioner. Hari ke14 adalah hari pertama pengamatan jumlah sel setelah diberi perlakuan timbal asetat. Pada saat dilakukan pengamatan mikroalga pada keempat media kultur mengalami perbedaan pertumbuhan yang sangat nyata. Hal yang sama juga terjadi pada jumlah kandungan klorofil total dari keempat media kultur tersebut mengalami perbedaan yang sangat nyata. Kandungan klorofil total pada mikroalga yang dikultur pada empat media yang berbeda memiliki nilai yang berbeda. Pada media kontrol memiliki kandungan klorofil total yaitu $80,49 \mu \mathrm{g} / \mathrm{ml}$, pada perlakuan 30 $\mathrm{ppm} 54,79 \mu \mathrm{g} / \mathrm{ml}$, perlakuan $50 \mathrm{ppm} 50,02$ $\mu \mathrm{g} / \mathrm{ml}$, dan pada media perlakuan $100 \mathrm{ppm}$ yakni $9,13 \mu \mathrm{g} / \mathrm{ml}$.
Perlakuan pemberian senyawa timbal asetat dengan konsentrasi 100 ppm memiliki nilai kandungan klorofil total paling sedikit dibandingkan dengan perlakuan dengan konsentrasi 50 ppm dan $30 \mathrm{ppm}$. Hal ini dapat disimpulkan bahwa pada hari pertama pemberian timbal asetat juga memberikan dampak terhadap nilai dari kandungan klorofil total yang dikandung oleh mikroalga Dunaliella sp. semakin besar konsentrasi logam berat timbal asetat yang diberikan maka semakin besar pengaruhnya terhadap nilai kandungan klorofil total pada mikroalga Dunaliella sp tersebut.

Kandungan klorofil total pada ekstrak hari ke 30, wadah kontrol mengalami penurunan yang cukup drastis dari $80,49 \mu \mathrm{g} / \mathrm{ml}$ menjadi $34,99 \mu \mathrm{g} / \mathrm{ml}$ jumlah kandungan yang menurun yaitu sebesar $45.5 \mu \mathrm{g} / \mathrm{ml}$ penurunan yang terjadi sangat besar dibandingkan dengan ekstrak yang diberi senyawa timbal. 


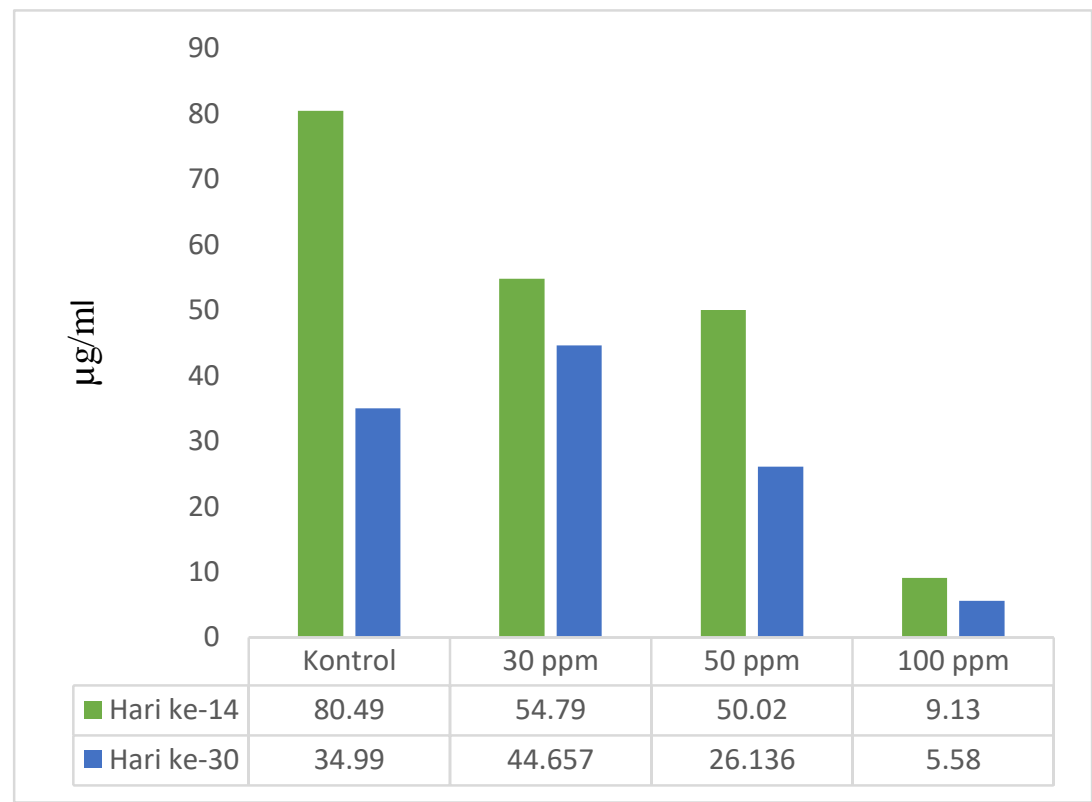

Gambar 5. Diagram perbandingan Kandungan klorofil total Dunaliella sp pada media kontrol, 30 ppm, 50 ppm dan 100 ppm.

Berdasarkan grafik di atas dapat dilihat bahwa terjadi perbedaan antara jumlah kandungan klorofil total pada hari ke-14 dan ke-30. Pada hari ke-14 Kandungan klorofil total tertinggi terjadi pada media kontrol dan jumlah kandungan klorofil total terendah terjadi pada media kultur dengan pemberian timbal senyawa asetat 100 ppm sedangkan pada hari ke30 kandungan klorofil total tertinggi terdapat pada media kultur yang diberi perlakuan timbal asetat. Penurunan jumlah kandungan klorofil total hari ke-14 dan hari ke-30 pada media kontrol yaitu sebesar $45,5 \mu \mathrm{g} / \mathrm{ml}, 30 \mathrm{ppm}$ yaitu $10,133 \mu \mathrm{g} / \mathrm{ml}, 50$ ppm $23.884 \mu \mathrm{g} / \mathrm{ml}$ dan $100 \mathrm{ppm}$ mengalami penurunan sebesar $3.55 \mu \mathrm{g} / \mathrm{ml}$. Hal yang sama juga terjadi pada penelitian Balaria dkk (2016), dimana pada fase eksponensial jumlah kandungan pigmen tertinggi terdapat pada media kontrol namun pada fase kematian jumlah kandungan tertinggi terdapat pada media perlakuan.

Pada media kontrol jumlah kandungan klorofil total dari hari 14 ke hari 30 mengalami penurunan lebih dari setengah, hal ini berbeda dengan 3 media perlakuan lainnya yang mengalami penurunan tidak sampai setengah jumlah kandungan dari hari ke 14 . Penurunan jumlah kandungan klorofil total yang tidak terlalu besar pada media perlakuan disebabkan karena mikroalga mempertahankan kandungan klorofilnya untuk mempertahankan hidup. Hal ini menurut Nio (2012) disebabkan karena pigmen klorofil berfungsi dalam proses fotosintesis dimana pigmen klorofil terletak pada kloroplas, sel-sel tersebut memiliki kemampuan menyerap energi cahaya. Mane dkk (2010) dalam Hatta (2013) mengatakan adanya peningkatan kandungan klorofil pada lingkungan yang memiliki kondisi stres di antaranya adalah untuk mempertahankan hidup. Suyitno (2008) menyatakan meningkatnya kandungan pigmen bersamaan dengan meningkatnya proses fotosintesis. Hal ini diasumsikan bahwa pada wadah yang diberi senyawa timbal mengalami peningkatan konsentrasi kandungan klorofil total untuk mempertahankan hidup Dunaliella sp. 


\section{KESIMPULAN}

Berdasarkan hasil penelitian yang dilakukan, maka dapat disimpulkan bahwa:

1. Efek senyawa senyawa timbal asetat pada pertumbuhan mikroalga Dunaliella sp yaitu menyebabkan kematian jumlah sel yang sangat drastis, namun masih ada beberapa sel Dunaliella $\mathrm{sp}$ yang mampu bertahan hidup.

2. Kandungan klorofil total hari ke-14 pada media kontrol yakni $80,49 \mu \mathrm{g} / \mathrm{ml}$, 30 ppm 54,79 $\mu \mathrm{g} / \mathrm{ml}, 50$ ppm 50,02 $\mu \mathrm{g} / \mathrm{ml}$ dan $100 \mathrm{ppm} 9,13 \mu \mathrm{g} / \mathrm{ml}$. Sedangkan kandungan klorofil total hari ke-30 pada media kontrol yaitu $34,99 \mu \mathrm{g} / \mathrm{ml}, 30 \mathrm{ppm} 44,657 \mu \mathrm{g} / \mathrm{ml}, 50$ $\mathrm{ppm} 26,136 \mu \mathrm{g} / \mathrm{ml}$ dan 100 ppm 5,58 $\mu \mathrm{g} / \mathrm{ml}$.

3. Pada hari ke-14 kandungan klorofil total tertinggi terdapat pada media kontrol diikuti pada media perlakuan 30 ppm, 50 ppm dan kandungan terendah terdapat pada 100 ppm. Pada fase ini semakin besar konsentrasi logam berat timbal asetat semakin kecil kandungan klorofil total yang terkandung. Sedangkan pada hari ke-30 kandungan klorofil total tertinggi terdapat pada media kultur perlakuan senyawa timbal asetat dan jumlah penurunan kandungan klorofil total terbesar terdapat pada media kontrol.

\section{DAFTAR PUSTAKA}

Abidin, D. \& Trihandaru, S. (2009). Monitoring densitas optik Dunaliella salina dengan optical densitometer sederhana serta uji kandungan klorofil. Prosiding Seminar Nasional Sains dan Pendidikan Sains IV. (hlm. 602). Salatiga, Indonesia: Departement of Science and Math, UKSW Salatiga.
Balaria, G. Y., Kemer, K., \& Mantiri, D.H. M. (2017).Pemisahan Pigmen Pada Mikroalga Dunaliella salina Yang Telah Diberi Senyawa Timbal Asetat.Jurnal Pesisir dan Laut Tropis. Volume 1 Nomor 1 Tahun 2017.

Harbone, J.B. 1987. Metode Fitokimia Penuntun Cara Modern Menganalisis Tumbuhan, Diterjemakan Oleh : Padawinata K. \& I. Soediro. Penerbit ITB Bandung.

Hatta, M. 2013. Kajian Pengaruh Salinitas terhadap Pertumbuhan, Kandungan Polifenol, dan Respons Fotosintesis Pada Tanaman Vetiveria zizanioides (L.) Nash. Di akses 5 Desember 2020 dari https://emhatta.wordpress.com/20 $13 / 04 / 2$

Kemer K., Mantiri D. M. H., Rompas R. M., Rimper J. R., Margyaningsih N. I., 2020 Transmission electron microscope analysis upon growth of lead acetate treated microalga, Dunaliella sp. AACL Bioflux 13(2) : 849-856.

Nio. S.A. 2012. Evolusi Fotosintesis pada Tumbuhan. Jurnal IImiah Sains. Vol.12. No.1

Romihartono, K dan Juwana, S. 2005. Biologi Laut. IImu Pengetahuan Tentang Bioat Laut. Djambatan. Jakarta.

Simanjuntak G., Mantiri D., Kemer K., 2016 Pengaruh Senyawa Merkuri Klorida $\mathrm{HgCl}_{2} \quad$ Terhadap Pertumbuhan dan Kandungan Pigmen Klorofil Mikroalga Botryococcus brauii. Jurnal Pesisir dan Laut Tropis. Volume 2 Nomor 1 Tahun 2016. 
Suyitno, A.M. 2008. Klorofil/ Pihmen Fotosintesis. Fakultas Matematika dan Ilmu Pengetahuan Alam. Universitas Negeri Yogyakarta.

Widowati, W. 2008. Efek Toksik Logam Pencegahan dan Penanggulangan
Pencemaran. Yogyakarta: Penerbit Andi Nomor 1 tahun 2018.

Wong, S.L.,Wainwright., Pimenta. J. 1995. Aquatic Toxicology. Elsevier Science Inc;USA. 